\title{
Doença e Morte na Umbanda Branca: A Legião Branca Mestre J esus
}

\section{I llness and Death in the White Umbanda: The Master J esus White Legion}

\author{
Daniela Torres de Andrade Lemos* \\ Universidade de São Paulo - USP, Ribeirão Preto, São Paulo, Brasil \\ José Francisco Miguel Henriques Bairrão** \\ Universidade de São Paulo - USP, Ribeirão Preto, São Paulo, Brasil
}

\begin{abstract}
RESUMO
Neste artigo expõem-se e analisam-se as concepções de doença e morte presentes em um renomado centro de cura espiritual, mediante procedimento etnográficos e a consideração dos seus implícitos. Subjacente ao surgimento da Legião Branca Mestre Jesus conta-se a história de uma família de índios cujos fundadores, depois de mortos, se unem no "plano espiritual" para atrair e reunir os seus membros que entretanto se haviam dispersado. Esta narrativa parece ser uma metáfora do encontro e desencontro entre colonizadores e suas vítimas africanas e indígenas. A doença é significada como um sinal de pertencimento a essa família e o fato dos "médicos" serem entendidos como mortos, propõe uma relação de familiaridade com a morte. A concepção reencarnacionista propicia a composição de laços entre biografias diversas, interligando uma revisão da própria identidade a memórias sociais da escravidão, da subjugação colonial e do etnocídio indígena.
\end{abstract}

Palavras-chave: Etnopsicologia, Cultos afro-brasileiros, Rituais de cura, Morte, Religião e saúde.

\begin{abstract}
This article sets out and analyzes the concepts of illness and death present in a renowned center for spiritual healing, through ethnographic procedures and consideration of their implicit. Underlying the emergence of the Legião Branca Mestre Jesus tells the story of a family of Indians whose founders, when dead, have joined in the "spiritual plane" to attract and bring together its member, however, had dispersed to. This narrative seems to be a metaphor for the agreements and disagreements between settlers and their indigenous and africans victims. The disease is meant as a sign of belonging to this family and the fact that "doctors" are seen as dead, proposes a relationship of familiarity with death. The reincarnation concept enables the formation of bonds between various biographies, linking an examination of his social identity to memories of slavery, colonial oppression and ethnic cleansing of the indigenous.
\end{abstract}


Keywords: Ethnopsychology, Afro-brazilian cults, Cure rituals, Death and dying, Religion and health.

\section{Introdução}

Os rituais umbandistas de consulta a espíritos foram descritos por Brown (1994) como tendo, em sua maioria, o tema principal do cuidado a todo tipo de doença. A autora chama a atenção para a forma como alguns umbandistas se vestem, que na sua opinião se assemelharia a uniformes de hospital e que tal vestimenta, apesar de narrada como uma escolha casual por parte dos seguidores, confere aos rituais uma aparência que se assemelha aos hospitais. Brown (1994) ainda ressalta que essas consultas (cujo tema mais frequente são casos de doença) conferem especificidade ao sentido da caridade na umbanda, valor este muito presente nas religiões cristãs e em especial no kardecismo. Segundo esta autora, a caridade no kardecismo é praticada de maneira impessoal, baseada em donativos financeiros não recíprocos que partem unilateralmente dos mais ricos para os mais pobres, tornando estes últimos apenas objetos de caridade e não companheiros de religião. Esta concepção teria como efeito a limitação da participação da classe média e a impossibilidade de participação das classes baixas. A umbanda, no entanto, através das consultas espirituais referidas a espíritos humildes, propicia um entendimento mais simétrico e, por assim dizer, democrático da caridade. Nela o conceito de caridade é compreendido como uma forma ritual de cuidado espiritual, o que, segundo a autora, opera em sentido oposto ao kardecista, no sentido da inclusão das classes baixas (que saem da posição de meros receptores da caridade alheia para a de cuidadores, mediante a execução dos ritos), inclusive oferecendo os terreiros alguns serviços a que esse público tradicionalmente não teria acesso, como consultas médicas, odontológicas e até mesmo jurídicas. Montero (1985) reconhece igualmente a importância das práticas de cura na umbanda, inclusive, como um importante recurso de conversão religiosa e de atração de novos participantes.

No entanto o caso exemplar que aqui será considerado, a Legião Branca Mestre Jesus, tipifica uma forma bastante peculiar de umbanda, definida pelos líderes do terreiro como "umbanda branca", que seria, segundo eles, uma forma de culto umbandista em confluência com o espiritismo kardecista, tida por eles como mais adequada às práticas de cura.

Curiosamente esta concepção evoca a tese de Camargo (1961) a respeito da existência de um contínuo mediúnico entre kardecismo e umbanda. Apesar de Cavalcanti (1983) afirmar que essas duas formas de experiência religiosa são distintas e devem ser pensadas a 
partir de elementos internos a cada uma dessas religiões, pode-se dizer que, pelo menos neste caso, parece confirmar-se a hipótese de contínuo mediúnico: ao dar ouvidos ao próprio grupo e à forma como ele propõe as suas concepções e seus elementos internos, encontramos na LBMJ uma síntese de contribuições tanto do kardecismo quanto da umbanda, devido à própria fusão desses elementos no caso específico do terreiro em questão. Aliás, conforme os membros da LBMJ costumam repetir, a "umbanda branca" (tipo de umbanda praticado pela LBMJ) é um tipo de ritual umbandista que está entre a umbanda sete-linhas, mais próxima do candomblé, e o espiritismo kardecista. Ou seja, a LBMJ se reconhece como umbandista, mas de um tipo de umbanda que se diferencia voluntariamente tanto daquela que localmente é conhecida como a umbanda "das sete linhas", quanto da pura e simples "mesa branca" kardecista, o que nos remete à ideia de contínuo de Camargo.

De toda a forma, é fato que, enquanto eles proliferam relativamente ao espiritismo, inexistem estudos específicos sobre a significação atribuída à morte na umbanda, e ainda menos sobre a sua relação com o adoecer, não obstante a doença ser um tema bastante relevante no culto (Magnani, 2002; Negrão, 1989). A realização da pesquisa de que se originou este artigo tem o sentido de contribuir para sanar essa lacuna.

\section{Método}

A umbanda não é uma religião codificada, além de não contar com um órgão unificador eficiente, 0 que the confere um caráter especialmente múltiplo e flexível. Tendo isso em mente, não seria possível abordar as questões a que este estudo se dedica, a não ser apenas em caráter circunscrito a um grupo específico, preferencialmente algum cuja excepcional exemplaridade, no atinente ao tema em pauta, seja reconhecida pela generalidade dos seus pares.

A este respeito e a propósito do estudo psicológico da experiência religiosa, Belzen sublinha que A generalização ocorre na apresentação de casos típicos, não por casos estocásticos, e especialmente pela elucidação da validade pela intensa relação intersubjetiva (BELZEN, 2010, p. 155).

Para a obtenção dos resultados, recorreu-se a entrevistas semiestruturadas com os membros mais antigos e atuais líderes do terreiro, no intuito de recuperar a sua história e os significados ligados aos temas de doença e morte, após a assinatura de um termo de consentimento que possibilitou a utilização das informações obtidas. Para alcançar o objetivo proposto, a história da instituição e aspectos biográficos dos participantes foram também considerados. 
Foram utilizados ainda documentos cedidos pela instituição, tais como atas, jornais, registros fotográficos e audiovisuais.

Esses recursos por si só não teriam sido suficientes, tendo-se mostrado indispensável a frequência e participação regular nos cultos (desde meados de 2007), combinando método etnográfico (observação participante, registros em diário, conversas informais) e elementos da técnica psicanalítica, nomeadamente a analise da transferência, permitindo aos pesquisadores reconhecerem-se no lugar a eles atribuído no curso da interlocução com o campo, para efeito de poderem precisar o alcance e sentido daquilo que Ihes era mostrado ou dito. Segundo Bairrão (2005), o pesquisador é sempre interpretado e posicionado segundo a lógica própria do campo em que está inserido, e é com base nessa relação, através desse lugar atribuído ao pesquisador, que ele pode compreender o sentido do que Ihe é dito.

De fato, conforme Devereux (1997), o trabalho etnográfico não deve se basear apenas em observações, sem que haja uma implicação do pesquisador e de suas próprias percepções. Ao contrário, o autor utiliza-se dos conceitos de transferência e contratransferência, derivados da psicanálise, para explicitar que o pesquisador deve estar atento ao lugar em que é colocado pelos seus interlocutores em campo (transferência) e ao modo como sente e percebe a relação com eles, observando a si mesmo (contratransferência).

Portanto, um importante fator a ser considerado é a trajetória dos pesquisadores em campo, Um dos autores foi interpretado como médium e recebeu, como muitos dos consulentes que assim são vistos, um convite para se preparar para integrar o corpo mediúnico, com a especial "missão" de realizar a pesquisa. Foi então admitido em um curso que teve a duração de seis meses, no transcorrer do qual foi iniciado a regras de comportamento (como o uso de uniformes) e explicações de rituais e rotinas do Centro. Além disso, a participação no curso foi parte importante do procedimento de pesquisa, pois foi a maneira encontrada para conseguir autorização para que se pudesse ter um olhar o mais interno possível relativamente à Legião Branca Mestre Jesus, o que não seria possível do ponto de vista de um consulente. Concluído o curso, o pesquisador passou a ser considerado "médium da casa" e a exercer atividades de cambono (médium auxiliar que, pelo menos no decorrer dessa função, não incorpora) concomitantemente à realização de registros para a pesquisa. Portanto, acedeu a um lugar ao mesmo tempo interno e diferenciado, pois foi-lhe facultado o acesso a lugares que outros frequentadores não poderiam participar, com a justificativa de que a autorização seria para fins de pesquisa. Ser interpretado como parte da "família espiritual" LBMJ, ainda que como pesquisador, e ter sido incluído, como igualmente costuma ocorrer com vários outros 
consulentes (muitos que, inclusive, dizem ser de outras religiões), revelou muito sobre esse grupo, assunto que será tratado adiante.

Além de frequentar o Centro durante os dias de atividades normais (segundas, quartas e sextas), também se esteve presente em dias festivos (normalmente aos sábados) e se realizaram entrevistas com antigos médiuns e pessoas ligadas à história da Legião Branca Mestre Jesus, em horários e locais previamente combinados.

Todos os dados obtidos foram interpretados não apenas segundo $o$ que foi falado, mas também com base nos significados que emergem das ações e na rotina do terreiro. Lutz (1992), a respeito desse conhecimento que não é explicitado, ou seja, o conhecimento implícito, diz que este deve ser resultado de uma negociação de significados entre o pesquisador e o sujeito estudado, resultando em proposições acerca de uma forma particular de conceber a si e ao outro, especificável apenas caso a caso. O resultado, portanto, foi fruto de uma combinação de significados entre $o$ que os pesquisadores escutaram e perceberam e o que os médiuns do Centro disseram, não apenas em palavras, mas por meio dos seus atos e práticas rituais.

Um ponto importante a respeito da forma como foi interpretado o que foi ouvido, é a recusa a atribuir significados exteriores à construção de sentidos pela própria comunidade estudada. Em vez disso, tratouse de dar voz aos participantes e revelar sentidos implícitos às suas narrativas (em conformidade com a noção de inconsciente lacaniana), para o que é fundamental aprender e apreender a sua linguagem e verificar o que com ela se enuncia, nos próprios termos em que é referido, sem colonizá-lo por outros referenciais (Bairrão, 2005).

Deste modo, em relação a todos os fatos contados, o intuito deste estudo não foi julgar tais histórias do ponto de vista da realidade objetiva, mas sim compreender como essas narrativas permitem depreender a cosmovisão e concepções éticas vigentes entre os viventes participantes da Legião Branca Mestre Jesus. Os resultados obtidos remetem tanto a descrições de rituais concretos e observáveis, como a histórias e concepções relacionadas à espiritualidade. Tais aspectos são vividos pelos participantes como igualmente verdadeiros e a sua compreensão é indispensável a uma reconstituição fiel do seu entendimento de doença e morte.

O projeto foi inicialmente submetido e aprovado por comitê de ética em pesquisa e a pesquisa foi autorizado pelos dirigentes do Centro em forma da assinatura de Termo de Consentimento Livre e Esclarecido.

\section{Resultados e análises}

\subsection{O Espaço}


A localização do Centro, na cidade de Santa Rita do Passa Quatro, tem forte significado. A cidade teria sido escolhida pela tribo por ser um lugar especial em relação aos outros. Segundo J osé Luiz Paiz, um antigo médium e ex-dirigente,

\begin{abstract}
“Santa Rita é uma cidade, assim, que tem um certo privilégio de vibrações. A religiosidade é muito grande e Santa Rita de Cássia é uma santa católica, naturalmente é uma entidade espiritual de Luz, que ela tem... Ela faz muita coisa pro povo da cidade, para quem procura na cidade também; muita gente é beneficiada por ela. É, tem alguma coisa a ver com a Santa, realmente. Muita gente alcança, assim, graças, como eles falam no catolicismo. E lá dentro do Centro não é a primeira vez, muitas pessoas me falam isso."
\end{abstract}

O local do Centro, portanto, não foi escolhido por acaso. Acima da cidade, no "plano espiritual", conta-se que há uma colônia espiritual, habitada por espíritos superiores responsáveis por oferecer sustentação a uma intensa movimentação espiritual na região. Nessa colônia, chamada Estrela da Guia - nome também dado ao Centro fundado por Meire (filha do médium fundador Roberto Zerbetto) e por seu marido, igualmente localizado em Santa Rita do Passa Quatro estariam presentes muitas das entidades chefes da LBMJ. Segundo esta médium, "a colônia... pega toda a região desses centros, onde tem um buraco espiritual onde são retiradas entidades das trevas. Por isso tem muitos hospitais em volta. Com a subida das entidades, ha muita contaminação das energias. Precisam dar sustentação espiritual à região através da religião, por isso a grande religiosidade de Santa Rita".

Considera-se que há também um grande hospital espiritual em cima da sede física da LBMJ, com nove andares, cada um em uma faixa vibratória, destinados a espíritos em diferentes graus de evolução.

Chegar à casa matriz não é tarefa difícil. Por sua notoriedade, o Centro (popularmente conhecido como "Centrão de Santa Rita" está incluído em guias oficiais da cidade e é amplamente conhecido pela maioria dos moradores. Alguém que chegue sem 0 endereço, facilmente 0 encontrará apenas perguntando ao primeiro que encontrar. Ocupa todo um quarteirão. A sua fachada, pintada de azul claro, como aliás o interior, tem no meio grande porta de madeira com o símbolo da LBMJ em cima (uma estrela amarela de seis pontas, contendo, no meio, as letras LBMJ em azul e, ao redor, o escrito "Legião Branca Mestre Jesus", também em azul). O formato do portal, como aliás todos os detalhes arquitetônicos, não são casuais, tendo sido determinados minuciosamente por uma das entidades fundadoras, o caboclo Tuamba. 
Em dias de atendimento ao público (às quartas e sextas-feiras) esta porta se abre perto das seis horas da tarde para a distribuição de senhas para os atendimentos e, mesmo antes de aberta, haverá uma grande fila. As senhas têm cores diferentes segundo o motivo da procura e uma numeração por ordem de chegada. São distribuídas na secretaria, logo à esquerda de quem entra pela porta principal.

Com a senha as pessoas vão entrando para o salão principal, mas o "trabalho" no entanto só começará às oito horas da noite. Entretanto, os consulentes ouvirão orientações tais como evitar carne vermelha (nos dias de lá ir), não usar roupas curtas, escuras ou transparentes, permanecer em prece em silêncio e, principalmente, admoestações doutrinárias sobre a própria responsabilidade ("merecimento") no processo de adoecimento, sobre a transitoriedade da vida e sobre o valor e a importância da fé no "Mestre Jesus", assim como prédicas a respeito da caridade.

Todo o ambiente é iluminado por luz fraca, permanecendo numa semi-penumbra. As imagens religiosas e outros objetos do altar central (congá) e dos altares laterais ficam iluminadas por lâmpadas em cor azulada, criando um efeito esteticamente impactante. O tom geral é de silêncio e recolhimento. Geralmente ouve-se uma música de fundo suave, a "Ave Maria" de Schubert.

No salão principal há dois espaços delimitados por uma mureta. Um, mais próximo da porta, é composto por dois grupos de bancos, onde os consulentes se sentam. Do lado esquerdo de quem entra, ficam os acompanhantes; e do lado direito, aqueles que passarão por consulta ou cirurgia. Na parede mais próxima da entrada existe de um lado uma grande imagem de Iemanjá, algumas espadas de São-Jorge (planta cujas folhas lembram o formato de uma espada) e várias estatuetas de caboclos, cada uma com uma pequena placa em frente indicando seu nome (entre outros, Potiguara e Jupira).

Do outro lado, também próximo à porta de entrada, ficam outras imagens de caboclos, uma fonte artificial de água com outra estátua de Iemanjá e um bebedouro. Mais ao fundo, passando-se uma mureta, é a área onde fica o terreiro propriamente dito posto que, na LBMJ, esta denominação aplica-se exclusiva e tecnicamente apenas a essa área, na qual no começo e ao final todos os médiuns se reúnem e onde se processam as incorporações. O congá é uma espécie de altar que como que adentra a parede que fica ao cimo do terreiro e em frente à entrada principal. Ao centro fica uma estátua de Jesus (cuja dimensão apenas é ultrapassada pela primeira imagem de lemanjá anteriormente mencionada). A imagem abre a mão direita em direção ao chão e com a esquerda aponta o seu coração, e não possui cruzes nem espinhos. Ao seu lado colocam-se flores, algumas espadas de São-Jorge e dois grandes potes de água. Abaixo do congá, no chão, existem algumas tábuas, com facas cravadas e pontos riscados. São os "pontos" das principais entidades do Centro, 
descritas pelos médiuns como aquelas que têm seu "ponto firmado" e que coordenam e dão sustentação aos rituais. A ordem em que essas tábuas são colocadas no chão segue uma sequência hierárquica. Do lado oposto ao congá, ainda no terreiro, mas junto à cerca e próximo da área dos consulentes, ficam as cadeiras onde se sentam os médiuns, de um lado os homens (à esquerda, quando se chega da rua) e de outro as mulheres (à direita). O chão desse espaço delimitado, chamado terreiro, é feito com piso de cor preta, com exceção de uma grande cruz, desenhada ao centro em piso branco. Não se pode pisar nessa cruz, exceto médiuns depois de incorporados ou durante as sessões espirituais (um específico tipo de tratamento espiritual que adiante será descrito).

As salas onde são feitas as consultas de saúde e as cirurgias espirituais estão sempre de luzes apagadas e são divididas por uma cortina branca. De um lado da cortina, próximos à porta, ficam bancos onde as pessoas aguardam serem chamadas e uma pequena imagem de J esus com uma vela acesa. Do outro lado da cortina, onde estão os cambonos (médiuns desincorporados) e um ou dois médiuns incorporados por entidades médicas (em geral caboclos), fica uma bancada de alvenaria com um colchão em cima, coberto por lençol branco, uma mesa onde os médiuns ajudantes fazem anotações, diversos papéis, um pouco de álcool, velas e água.

Estas salas são dispostas lado a lado em um corredor paralelo ao salão principal anteriormente descrito, que fica à direita de quem entra pelo portão principal, mas tem uma porta independente para a rua. É um corredor longo, com cinco salas e um balcão com água logo ao lado dessa porta de saída. As pessoas em geral entram pelo portão que fica no meio da quadra e saem por este. A sessão espiritual, os passes magnéticos e os descarregos (vide adiante) são realizados no próprio terreiro.

Há também outro corredor, onde existem diversos quartos para alojamentos de pacientes, em especial aqueles que moram longe e não têm possibilidade de se hospedarem em outro lugar. Este corredor fica à esquerda de quem entra no Centro, com acesso por uma porta logo ao lado da fonte artificial. Em sua entrada, há um pequeno espaço projetado no interior da parede, uma espécie de vitrine, com diversas imagens de pretos velhos. Enquanto as imagens de caboclos presentes no salão principal são enormes relativamente à sua iconografia mais habitual - o seu tamanho apenas é excedido pela imagem de Jesus (Oxalá?) no congá e pela de Iemanjá (Nossa Senhora?) no canto direito do salão principal - estas são verdadeiras miniaturas, muito delicadas, que impactam pela sua singeleza, criando um efeito de contraste entre "grandeza" e "humildade" que na umbanda são valores que respectivamente se associam aos Caboclos e aos "Pretos-Velhos". 
Há ainda algumas salas onde se realizam consultas e cirurgias, um refeitório e uma lavanderia. Há também vestiários, localizados à esquerda da entrada do estacionamento (no muro lateral do Centro), um masculino e um feminino. Em ambos há um espaço comum, onde ficam os pertences dos médiuns, dois banheiros e um pequeno altar, no canto esquerdo em relação à entrada, com uma imagem de Jesus. Ao lado do estacionamento, à direita de quem entra, existe outro terreiro, a céu aberto e com chão de areia, chamado pelos frequentadores de "mata", utilizado nas festas de Pretos-Velhos, de Três Santos (São Pedro, São João e Santo Antonio), de Rompe Mato e de Cosme e Damião.

Outras festas (rituais anuais) realizam-se em espaços exteriores ao quarteirão do Centro, tais como a festa de Sete Cachoeiras. Nesta, sempre realizada em uma cachoeira, ocorre um "cruzamento" (iniciação) que confirma o mesmo tipo de iniciação previamente realizado no terreiro (o médium é considerado "pronto" e está autorizado a incorporar).

Nenhum detalhe arquitetônico deixa de ter significado simbólico, a começar pelas vigas que sustentam o telhado do salão principal (em número de sete). Abaixo deste, a cruz branca desenhada no chão do terreiro é vista como o local onde se comunicam o plano espiritual e o plano físico, uma mais do que provável reminiscência da ideia africana de que os mortos vivem num mundo abaixo dos nossos pés (RIBAS, 1975), topografia simbólica que não parece ser percebida como contraditória com a ideia de um hospital e uma colônia espirituais respectivamente situados acima do Centro e acima e um pouco ao Norte do Município de Santa Rita (em direção a São Simão). É através dessa cruz que, literalmente, os espíritos a serem incorporados chegam e igualmente por seu intermédio que vão embora.

Na generalidade dos centros, no chão do salão central costuma ficar enterrado o principal "fundamento" do centro, sendo esse ponto considerado o mais sagrado e sede verdadeira da sua força espiritual. Em Santa Rita esta tradição manteve-se, porém sublinhada e composta com uma vinculação ao cristianismo. Não se deve pisar na cruz, tanto como um sinal de respeito a esse ponto de passagem espiritual entre o mundo dos vivos e o mundo dos mortos, como também para que não haja "contaminação" das energias contidas nesse local.

Na mesma linha da relevância atribuída aos pontos de passagem, outro exemplo é o caso da porta, que durante os rituais é aberta apenas periodicamente, a fim de que a entrada e saída de energias e espíritos possam ser devidamente controladas. Quando aberta, fica ao lado um médium incorporado por um caboclo com as mãos estendidas sobre a cabeça dos consulentes que saem, além de outro que defuma todo o local da passagem. 
Todo o trânsito dentro do centro é igualmente controlado, de forma que apenas os que forem passar por cada ritual ficam no local em que este acontece. Algumas vezes, como no caso da sessão espiritual, não pode haver nenhuma movimentação em lugar algum, pois nesse momento o controle das energias e espíritos deve ser ainda mais rigoroso, sob pena de algum médium entrar em desequilíbrio.

\subsection{Percursos: os Consulentes}

Nem todos os que procuram a LBMJ vão à procura de ajuda para problemas de saúde. Muitos a procuram em busca de ajuda para questões pessoais de qualquer natureza. Essas pessoas deverão, preliminarmente, passar por uma consulta de orientação. Esperarão sentadas nas cadeiras do salão principal e, quando seu número for chamado, guiadas por um cambono (médium auxiliar, desincorporado), adentrarão o terreiro para serem atendidas por um dos caboclos incorporados no momento, a quem dirão o motivo da sua ida. Receberão orientações e, algumas vezes, sugestões de banhos de ervas e de pequenos rituais que poderão realizar por conta própria (acender velas, por exemplo). Assim que terminar a consulta, a entidade passa a sua guia (colar) pelo corpo do consulente, num "passe" de limpeza. O consulente, se o desejar, pode então sair do terreiro.

Existem também os rituais de descarrego, realizados por pretosvelhos, também destinados à limpeza de "energias" negativas. A entidade pede que o consulente se ajoelhe à sua frente e então molha um ramo de arruda em um copo de água, respingando-a sobre o consulente e passando-o pela chama de uma vela, em movimentos sucessivos. Segundo o médium Paulo (ex-dirigente), a água tem a função de limpar as energias negativas, que são atraídas pelo galho de arruda e serão, em seguida, queimadas pela vela. Este ritual é muitas vezes realizado apenas com pertences ou fotos de pessoas que não estão presentes, levados por consulentes, seus familiares, amigos, ou um conhecido. Este mesmo procedimento, de atendimento à distância através de fotos ou pertences, pode ser feito em outros rituais, como consultas e cirurgias.

Muitos dos espíritos que se apresentam em transe nos vários rituais realizam também os passes, destinados à reorganização das energias do consulente ou como complemento cirúrgico, como um "curativo espiritual". A entidade coloca as mãos sobre a cabeça do consulente e depois faz repetidos movimentos com as mãos, de cima para baixo, na frente do corpo do consulente e atrás.

A consulta de saúde é o primeiro passo de quem chega à procura de tratamento para algum problema de doença. O consulente chega à sala de consulta de saúde, junto com vários outros portadores de 
senha, e aguarda. A porta da sala é fechada e então é feito um Pai Nosso por um dos médiuns ajudantes (cambono). No momento em que for chamado, o consulente vai para trás da cortina e relata seu problema ao espírito incorporado. Após o relato, a entidade médica passa as mãos, em movimentos repetidos, pela cabeça e corpo do consulente, de olhos fechados. Ao término do processo conversa e pode indicar banhos, uma cirurgia espiritual, cruzamento ou sessão espiritual. Depois que todos os presentes na sala já passaram pela consulta, a porta se abre e eles podem sair.

Os cruzamentos são mini-cirurgias espirituais, procedimentos rituais mais simples que a cirurgia propriamente dita. São feitos para reequilibrar as energias e são indicados isoladamente, quando não há necessidade de uma cirurgia espiritual convencional, ou como tratamento complementar da cirurgia. O procedimento é muito semelhante ao da cirurgia, mas geralmente feito com a pessoa em pé e sem a listagem das partes operadas. Todos que entram na sala devem esperar até que o último daquele grupo seja atendido, como na consulta de saúde.

A sessão espiritual é um procedimento ritual indicado ao consulente que, depois de passar pela consulta de saúde, recebe o diagnóstico de que sua doença se originou da influência negativa de algum espírito considerado obsessor. Ele então aguarda o final de todas as consultas, passes e cruzamentos, pois apenas depois de encerrados todos os demais procedimentos se dá início à sessão espiritual. Realizada no terreiro, a partir desse momento ninguém mais pode transitar pelo Centro e as portas principais se mantêm fechadas até o final da sessão. O motivo disso é que as energias presentes nesse ritual são consideradas demasiado "pesadas" e perigosas, devendo ser mantidas apenas no espaço do terreiro. Se as pessoas transitassem poderiam carregar tais energias e espalhá-las, o que poderia trazer prejuízos a todos.

$\mathrm{Na}$ sessão espiritual, o consulente vai ao terreiro e descreve seu problema a um médium incorporado por um caboclo. $O$ médium incorporado pede ajuda a outro, que se senta na cruz branca do terreiro e incorpora o espírito que estaria influenciando o paciente e causando sua enfermidade. O caboclo então conversa com este espírito, pedindo que ele saia da vida do consulente. Após este ritual de "desobsessão", o paciente estará livre dessa influência negativa.

Há ainda outro ritual, a sessão de limpeza espiritual, que pode ocorrer concomitantemente à sessão espiritual (ou seja, encerrados todos os demais "trabalhos"). É realizado em duas salas, localizadas no fundo do corredor principal, e descrito pelos médiuns como "mais forte". Os caboclos que a coordenam são da linha de Rompe Mato: Ogum da Mata e Jererê. Em uma das salas os próprios consulentes incorporam seus obsessores, após alguns procedimentos realizados pelo Caboclo, e são então doutrinados para que sua influência cesse. 
Esse doutrinamento é feito pelos cambonos, médiuns desincorporados, através de uma fala proferida ao pé do ouvido do consulente incorporado (normalmente estendido no chão, se contorcendo), aconselhando o obsessor a se retirar e oferecendo ajuda para isso. Segundo os médiuns, caso a entidade se recuse a sair, será obrigada, não tendo escolha. Conforme o Caboclo Jererê (incorporado pelo médium José Luiz), ele "ou sobe, ou desce: aqui o negócio se resolve de qualquer maneira". Este mesmo Caboclo se utiliza de uma faca sem corte, com a qual promove a "limpeza" das guias, e de uma mistura de sal grosso e vinagre de vinho tinto, que passa sobre as entidades mais "rebeldes".

A principal diferença entre os dois tipos de rituais anteriores é que na limpeza espiritual o obsessor incorpora no consulente, enquanto na sessão realizada no terreiro o obsessor incorpora em um dos médiuns.

Há também uma sala de sessão espiritual onde não há incorporação de obsessores, apenas consultas. Esta sala, segundo o Caboclo Pena Azul, é destinada a pessoas com transtornos psíquicos, tais como pânico, transtorno obsessivo compulsivo e depressão, que não poderiam ir para a primeira sala, pois lá "é muito forte".

Os que passarem pela sessão espiritual ou de limpeza espiritual serão os últimos a irem embora, antes do encerramento na sexta-feira. Depois disso, ficam apenas os médiuns e alguns consulentes que se hospedam ou desejam ver o encerramento. Ao término de tudo, segue-se a desincorporação que, tal como a incorporação, segue uma ordem hierárquica, de tal forma que o primeiro caboclo a chegar e o último a partir é sempre a entidade chefe da Casa.

Não há regras muito definidas ou formais para definir a chefia. Esta sempre é atribuída a um Caboclo do grupo fundador da LBMJ. De tempos em tempos, na ausência dos seus médiuns originais, estes podem incorporar em outros, que desta forma se habilitam a, algum dia, virem a ser "veículos" de uma entidade dirigente, o que por si só Ihes confere prestígio. Mas quem decide quem e por que período comandará o terreiro parecer ser assunto da família espiritual, limitando-se os médiuns a acatar os seus desígnios, o que no entanto não deixa de ocasionar tensões intragrupais, agravadas, muitas vezes, por divergências entre a direção espiritual do Centro (atributo, indiretamente, do médium que entretanto recebe a entidade com estatuto de chefia nesse período em função de comando) e a diretoria social, responsável pela condução administrativa da instituição (e composta habitualmente por outros médiuns). No período de realização da pesquisa o Centro foi dirigido sucessivamente por Potiguara (Médium J ozé Luiz Paiz), Cabocla Jupira (Médium Yvone) e Caboclo Pena Azul (Médium Paulo).

Muitas pessoas que procuram ajuda para problemas de saúde na sexta-feira recebem a indicação de uma entidade para passarem por 
uma cirurgia espiritual, realizada às quartas-feiras. Nesse dia, o atendimento se restringe à realização dessas cirurgias, mas a rotina é a mesma, inclusive seguindo a mesma sequência de início e encerramento do ritual. Os consulentes recebem números referentes às fileiras que deverão ocupar no salão principal e, do ponto de vista de quem entra, à direita ficam os que serão operados e, à esquerda, os acompanhantes.

As cirurgias espirituais são procedimentos rituais, sem qualquer intervenção física, realizadas por um caboclo com o status de entidade "médica" (normalmente uma entidade chefe). O consulente chega à sala de cirurgia, e tudo se passa da mesma maneira que numa consulta, com as salas dispostas da mesma forma e também seguindo a ordem das senhas. Os objetos rituais são os mesmos, mas há também um "medicamento", mistura de água e vinho branco, que passa por um procedimento ritual de "energização" e é oferecido em pequeníssima quantidade aos que passam pela cirurgia. Quando é chamado, aquele que passará pela operação deve tirar os sapatos e subir, sempre com a ajuda dos médiuns não incorporados, numa bancada com um colchão. Durante a cirurgia, a entidade diz a um ajudante, chamado de secretário, quais as partes "operadas", para que este as anote em um prontuário que fica arquivado no Centro. Estas partes que são indicadas pela entidade não são necessariamente as mesmas partes relacionadas à queixa do consulente, o que indica uma representação (simbólica) do corpo de um ponto de vista espiritual, nem sempre correlata com a enfermidade concreta. O espírito passa então pelo corpo do consulente um objeto preso à guia (colar) chamado "ponteiro", de metal pontiagudo, parecido com um punhal, como uma representação simbólica de um instrumento cirúrgico. Este objeto é sutilmente deslizado por algumas partes do corpo, sem no entanto haver qualquer perfuração ou corte. O médium incorporado também faz alguns movimentos com as mãos, como se retirasse algo invisível do corpo do paciente. De tempos em tempos, ele pede que todos orem um Pai Nosso, sobretudo em momentos "críticos", em que haja nervosismo por parte do consulente, alguma dificuldade derivada da doença, quando a doença a ser tratada é percebida como muito grave etc. Este "Pai Nosso" serve para manter a "corrente", ou seja, garantir o bom andamento da cirurgia e a proteção do local em relação a energias nocivas. Ao final de tudo, o paciente sai da bancada com a ajuda de um médium ajudante, que o auxilia a colocar os sapatos. Voltando ao seu lugar, recebe um pequeno copo descartável com o "medicamento" e alguns papéis com recomendações de conduta e dieta, para o "pós-operatório espiritual". Aguarda o atendimento de todos, como na consulta, e sai em conjunto com os demais da sala, para então aguardar a abertura da porta de saída do Centro. Após a cirurgia, pacientes com doenças 
mais graves, que estejam sozinhos (recomenda-se não dirigir no dia da cirurgia) ou que morem longe (mais de cem km de Santa Rita do Passa Quatro) devem permanecer nos alojamentos do Centro ou, se tiverem posses, em pousadas vizinhas.

\subsection{Percursos: os Médiuns}

As entidades podem eventualmente dizer que um consulente é um médium e, portanto, precisa desenvolver sua mediunidade. Tal comunicado pode ocorrer em qualquer momento dos rituais da Casa e, nos casos de doença, desenvolver a mediunidade pode ser determinante para o sucesso ou o fracasso do tratamento. Isto porque a mediunidade não desenvolvida, em alguns casos, é vista como a causa em si da enfermidade. A pessoa que é vista como médium recebe um papel explicativo e sugere-se a ela que passe a frequentar o curso de médiuns, realizado às segundas-feiras, com duração de um semestre. Se realmente quiser participar do curso, deve aguardar até que se forme uma nova turma.

Para frequentá-lo, o participante passa a entrar pelo estacionamento, localizado numa rua lateral em relação à entrada principal. Dá-se com um grande refeitório, logo à frente da entrada do estacionamento, onde ao final das sessões os médiuns se reúnem para comer sopa. O curso se inicia no mesmo horário que os trabalhos no terreiro, às oito da noite, e termina alguns minutos antes do encerramento. Durante o curso, o responsável pela aula falará sobre regras de funcionamento, sequência dos rituais, doutrina e mediunidade. Muitas vezes nas aulas passa-se muito tempo respondendo a perguntas relativas à mediunidade e falando sobre sensações relacionadas a esse tema. Recebe-se uma apostila e, no decorrer do curso, pode-se começar a "estagiar", ou seja, começa-se a ajudar nos trabalhos de quarta e de sexta-feira.

Deve-se, para isso, usar um uniforme. Para os homens, camisa, calça, meias e sapatos brancos. Na camisa, costura-se um bolso com o símbolo da LBMJ. Para as mulheres, é feito uma espécie de jaleco com comprimento cerca de quinze centímetros abaixo do joelho. Este jaleco deve ter um zíper que vá do colarinho até a altura do umbigo, ficando a parte de baixo sem abertura alguma, o que faz com que se assemelhe a um vestido. Também devem usar calças, meias e sapatos fechados brancos, sem salto. Não podem usar brincos grandes, maquiagem ou esmalte escuro nas unhas.

Os médiuns que já terminaram o curso, ou que vão à Casa em dia diferente da segunda-feira para estágio, entram direto para os vestiários. Ao chegarem, devem "bater cabeça" três vezes no altar sito no seu vestiário. Às oito horas, quando começam os trabalhos, no vestiário masculino toca-se uma campainha que pode ser ouvida também no vestiário feminino. Esta primeira campainha indica que 
todos devem se levantar e dar as mãos, em ordem hierárquica, em que os médiuns mais antigos ficam mais próximos da porta. Todos permanecem em silêncio até que soe a segunda campainha, que indicará que todos devem rezar o "Pai Nosso", entoado em uníssono e de forma ritmada. Ao final, todos saem devagar pela porta do vestiário e entram no terreiro por portas que, para os consulentes que chegam da rua, ficam à esquerda para os homens e à direita para as mulheres, nas paredes laterais, ao lado do altar. Nesse momento, os consulentes estão todos em seus lugares e a porta principal já foi fechada. Todos os médiuns entram e se sentam em suas cadeiras. Os médiuns iniciados se sentam na fileira da frente e os que ainda não fizeram a cabeça (não foram "cruzados") se sentam numa fileira mais ao fundo.

Depois de todos sentados, mulheres de um lado e homens de outro, um dos médiuns aparece pela porta dos vestiários com três defumadores. Um deles é utilizado pelo médium chefe para defumar toda a parte das salas e alojamentos. O outro fica com outro médium, que defuma a área propriamente dita do terreiro. Um terceiro permanece em frente ao congá. Depois de defumar o Centro, os dois médiuns retornam e solicitam aos demais se levantem para bater cabeça no congá. Em fila, um a um, batem a cabeça três vezes no congá e andam de maneira característica para trás, já trazendo consigo postura e gestual típicos da entidade incorporada, geralmente caboclos. Segundo Birman (1985) os caboclos são facilmente reconhecíveis no momento da incorporação, por soltarem gritos, baterem no peito e andarem de cabeça erguida, o que, de fato, visivelmente se confirma no caso dos médiuns da LBMJ.

Após a incorporação de todos os que forem incorporar no dia, médiuns incorporados e não incorporados vão para as diversas salas, com a ajuda de uma planilha com a distribuição dos que ficarão em cada uma. Apesar do clima convidar à meditação, os médiuns incorporados, ou mais precisamente, os caboclos e os seus assistentes, mostram-se extremamente ativos, permanecendo fixos nos lugares que thes foram atribuídos ou deslocando-se incessantemente pelo terreiro, aparentemente cumprindo tarefas bem definidas.

\subsection{O Tempo}

A história do Centro é contada pelos participantes sob dois pontos de vista distintos: o da perspectiva da história material e o da história espiritual.

Tudo teria começado na década dos 1940, como um Centro de "mesa branca" (kardecista). Lá se reuniam alguns parentes e amigos para reuniões, nas quais havia, além de incorporações, vários tipos de comunicação mediúnica. Relatou Luiz Paiz, antigo médium, pai de 
Jozé Luiz Paiz e um dos dirigentes históricos do Centro (entretanto falecido) que nessa altura havia comunicação por sons de batidas, chamada pelos médiuns de "tiptologia". O mesmo grupo também fazia doação de remédios homeopáticos aos pobres:

\begin{abstract}
“E tudo que fizemos em função da Casa, porque a Casa foi aberta por intermédio de uma farmácia. De uma farmácia que fazia caridade. E o professor Roberto, que era um grande conhecedor da história, era dono dessa farmácia, o prédio era dele... Então, durante o dia, ele ia para a escola, depois vinha e ele dava medicamento" (Luiz Paiz).
\end{abstract}

Era a chamada "farmácia homeopática dos pobres", atividade vinculada ao centro espírita de que viria a originar-se a Legião, chamado Casa de Caridade Maria Emília. Pode-se notar que os elementos da caridade e da inclinação às práticas de cura já se faziam presentes desde o início da história da LBMJ .

Segundo Brown (1994) a chegada da homeopatia ao Brasil, no final do século dezenove, teve forte influência do ideário cristão, principalmente do valor da caridade. Segundo a autora, nessa época era muito comum que os homeopatas abrissem clínicas de tratamento homeopático, sem custos, para os pobres. Como muitos dos grandes nomes do kardecismo nessa época eram também homeopatas, a história da homeopatia no Brasil e sua relação com o Kardecismo em muito influenciou o entendimento e prática da caridade nessa religião (e isso até aos dias de hoje). Foi a partir desse momento que começaram a se instituir as práticas benemerentes pelas quais o kardecismo ainda hoje é conhecido, como por exemplo os cuidados médicos e a doação de remédios, alimentos e vestuário aos "pobres".

O médium Roberto Zerbetto, dono do prédio onde se realizavam as reuniões, foi o principal protagonista do processo de fundação da Legião Branca Mestre Jesus. Foi ele que se destacou nesse culto de mesa branca e, após alguns conflitos, se separou do grupo para fundar a LBMJ, agora como um culto de umbanda branca.

As dissidências entre Roberto Zerbetto e o Centro Maria Emília começaram porque ele começou a incorporar um caboclo, dito o fundador espiritual da LBMJ, Pai Tuamba. Os médiuns do centro de mesa branca não viram com bons olhos a presença de uma entidade umbandista, o que teria provocado o afastamento de Roberto, que fundou então a Legião Branca Mestre Jesus, naquela época chamada Templo Beneficente Espiritualista Mestre Jesus. Note-se que as iniciais T.B.E.M.J. aparecem, até hoje, na placa que fica bem na entrada do Centro. Entretanto, o nome Legião Branca Mestre Jesus, cujo significado será explicado mais adiante, é o mais utilizado.

Esta história de fundação se assemelha muito com a narrativa mais difundida entre umbandistas a respeito do surgimento da umbanda, 
protagonizada por Zélio de Moraes, em Niterói. Durante uma sessão espírita de "mesa branca", este teria incorporado o espírito de um caboclo, o "Caboclo das Sete Encruzilhadas". Instado a se retirar pelos dirigentes do culto, por na qualidade de mestiço ou indígena, tal como igualmente sucedia com espíritos que se apresentavam como antigos africanos, ser considerado "atrasado", este teria anunciado e convocado uma sessão na casa do seu médium, na qual se fundaria uma prática espírita isenta desse tipo de confusão entre segmento social e grau espiritual. Teria então sido criado o que é visto, por muitos, como o primeiro terreiro de umbanda.

É claro que muito antes disso havia no Brasil práticas mediúnicas que envolviam espíritos indígenas e africanos escravizados, sendo que o mais provável é que a menor objeção social ao espiritismo europeu tenha sido inicialmente vista como uma possibilidade de aliança e de legitimação para os praticantes de ritos de possessão nativos, mais populares e muito perseguidos. No entanto em muitos casos (e até hoje) esta adesão foi mal recebida pelos adeptos de uma espécie de projeção da hierarquia social (e de certa forma racial) em supremacia espiritual, ocasionando conflitos e cisões que induziram à institucionalização da umbanda como uma religião independente.

Desde aquela época o médium Roberto Zerbetto já recebia um PretoVelho, o Pai João do Congo, entidade espiritual que deu início à prática de cirurgias espirituais e desempenhou um papel decisivo na fase de transição e consolidação do novo Centro (agora de umbanda). Os primeiros participantes eram membros da família Zerbetto, amigos ou vizinho. Mais tarde, chegou mais gente e todos se uniram para a construção da atual sede, em sistema de mutirão e arrecadando materiais para a construção. Nesta etapa e nas sucedâneas, até há bem pouco tempo, médiuns da família Paiz tiveram um papel de destaque.

Em Santa Rita do Passa Quatro, interior de São Paulo, por volta da década dos 1940, Roberto Zerbetto, à semelhança de Zélio de Moraes em Niterói e provavelmente seguindo uma tendência que deve ter se repetido um pouco por toda a parte, insurgiu-se contra o veto do centro de mesa branca em admitir a presença de entidades espirituais como o caboclo Tuamba e o preto-velho Pai J oão do Congo e fundou a LBMJ. Esse conflito, um veto à comunicação espiritual de entidades espirituais decalcadas de tipos sociais subalternos e desprestigiados pela ortodoxia kardecista, vai reproduzir-se e representar-se simbolicamente, também, numa outra história da fundação do Centro, a espiritual.

Há cerca de quinhentos anos, portanto aproximadamente na altura do "Descobrimento", uma família de índios "mortos" teria se unido para iniciar a preparação da criação no plano físico do Centro. O nome Legião Branca refere-se a essa família, uma legião de espíritos reunida com o intuito de realizar trabalhos de caridade, a que 0 
adjetivo "branca" faz referência. Duas entidades primas, Tuamba e Jussara, teriam se unido sob a orientação de seu avô, Pai Cacique, para a formação do grupo espiritual original. Têm diversos "filhos", como Acayama, Indaiá, Arajá, Tacuna, que ainda hoje, como todos os outros membros da tribo, são entidades que fazem parte dos trabalhos do Centro, seja incorporando nos médiuns, seja como "mentores" dos trabalhos.

O início da formação do Centro teria se dado portanto por volta da época do "descobrimento", por um lado marco de fundação do que viria a ser o Brasil (de certo modo a "coincidência" não deixa de ser uma forma de reafirmar uma referência simbólica da nacionalidade a uma ancestralidade indígena), mas por outro é sabido (e sofrido) que esse marco assinala o começo do extermínio de muitos nativos como e a dizimação de muitas etnias indígenas.

Esse dilema histórico reaviva-se nas entrelinhas da narrativa de origem contada pelos membros da LBMJ. A história da fundação da LBMJ permite depreender que a família que a teria originado, uma espécie de tribo simbólica representativa de todos os povos exterminados na época do descobrimento, incorporou em si e à sua maneira algo de aproveitável da cultura de quem os exterminou (o cristianismo) e teria vencido a morte e retornado para sanar problemas dos brasileiros da atualidade, interpretados como seus descendentes ("filhos").

Outra versão da história de fundação mantém a cifra mil e quinhentos anos, mas para dizer que a fundação começou há esse tempo atrás (portanto, um milênio antes do Descobrimento). Segundo esta, as condições na altura e nos duzentos anos seguintes foram tão terríveis que apenas espíritos com necessidade de expiação encarnaram nessa época, estando isentos disso o núcleo central da família.

Nesta versão mantém-se o valor significante de "mil e quinhentos" e a altura do Descobrimento como um período trágico, mas o núcleo da família já estaria protegido pela morte e não teria sido diretamente vitimizado. Os espíritos "mais evoluídos" não encarnavam no Brasil devido aos males do processo de colonização, ajudando em outro plano, na assistência espiritual aos demais índios mortos. Desta forma, a segunda versão não altera substancialmente a interpretação desse trauma histórico, apenas reforçando a antiguidade da linhagem espiritual da Legião e sublinhando que no seu estatuto real (espiritual) os fundadores não foram atingidos.

Todas as entidades que incorporam no Centro, como dito anteriormente, são compreendidas como parte de uma mesma família, mas também todos os médiuns que fazem ou fizeram parte do Centro e os pacientes que batem à sua porta, em última análise, são vistos como parte dessa família, sendo que os irmãos "menores" são os que ainda precisam manter-se na gangorra do "reencarnar-se" e do "desencarnar-se". 
A história da "família espiritual" que é a LBMJ também parece ser uma metáfora da história do país, imbuída de valores cristãos como a caridade e a fraternidade (os laços familiares), combinados a um sentido geral de sobrevivência do derrotado à morte e seu retorno para regenerar os vivos. Este tipo de alusão alegórica e elaboração de uma memória social é muito frequente na umbanda e aparece igualmente na narrativa da fundação da Legião Branca nesse plano espiritual.

\subsection{O Espírito}

A compreensão de espírito sobre o qual se baseiam as concepções da LBMJ é fundamental para a compreensão de um importante ponto ligado às suas noções de doença e morte: seu caráter profundamente inclusivo.

De acordo com essa noção, os seres mais evoluídos (como seria o caso das entidades da tribo que deu origem à LBMJ) não precisam mais reencarnar, ou seja, não vivem mais na terra sob a forma humana. Entretanto, o compromisso desses espíritos teria se mantido em relação aos menos evoluídos que ainda reencarnam, os seres humanos. Este caráter inclusivo também aparece na ênfase dada pelo centro à caridade, vista e ressaltada sempre como ponto fundamental. Tal preceito seria algo como uma máxima baseada na lógica "ajude e será ajudado", máxima presente constantemente nas falas dos médiuns e entidades do Centro, que sempre mencionam a importância da caridade cristã.

\footnotetext{
"A mediunidade constitui a maneira mais simples de praticarmos a verdadeira caridade, a caridade espiritual. Cooperando com os espíritos curadores, ajudamos na tarefa de aliviar os que sofrem e como instrumento dos espíritos educadores, contribuímos para o adiantamento moral e espiritual de nossos irmãos e também o nosso" (Trecho da apostila utilizada no curso de médiuns).
}

Há inclusive um cuidado especial por parte das entidades em se apresentarem de maneira mais próxima e acolhedora possível ao consulente. O preto-velho Pai João do Congo, por exemplo, é descrito como um grande médico e cientista.

A função dos pretos velhos dentro do culto, tal como o papel atribuído a eles na fundação, pode fornecer importantes elementos para se compreender certos dilemas históricos da realidade brasileira. $\mathrm{Na}$ Legião Branca, os pretos-velhos, embora não apareçam como os principais atores, são quem planeja e fica na retaguarda de todos os trabalhos. Segundo Paulo, médium do Caboclo Pena Azul, são eles que "pegam no pesado" e os primeiros a entrar e os últimos a sair. 
Foi também o preto-velho João do Congo a primeira e única entidade a realizar cirurgias espirituais, logo no início da Legião Branca (do ponto de vista da história material).

Os pretos-velhos (figuras de antigos escravos) têm certo destaque, mas as personagens centrais da narrativa e na cena mais visível do culto, quem aparece como pioneiro e principal protagonista é o indígena.

Segundo Brown (1994), a umbanda branca ou "desafricanizada", como é o caso da LBMJ, tem um caráter marcadamente nacionalista. Nessa forma de culto, entidades relacionadas à história brasileira (como os caboclos e pretos-velhos) têm maior destaque e, de certa maneira, a função de afastar do culto umbandista entidades vistas pela autora como mais africanas, como os exus. Brown, ao desenvolver sua análise, parece não se dar conta de que os exus não são nem mais nem menos africanos do que os pretos velhos e os caboclos (Rotta, 2010) pois não se pode pensar num puro espelhamento da ordem social do panteão umbandista desconsiderando a lógica subjacente. O efetivamente africano é o modo de pensar e de construir a religião em sua estrutura e não um ou outro personagem. Em uma observação de campo mais profunda, observa-se que há uma íntima ligação entre pretos velhos e exus e mesmo entre estes e caboclos, embora isto fique oculto aos olhos de observadores eventuais.

Segundo Cavalcanti (1983), a noção de pessoa no espiritismo é permeada pela concepção de morte e as relações entre vivos e mortos, concepção compatível com o que se ensina na Legião Branca, cujo entendimento de espírito pode ser sintetizado na idéia de que há uma parte da pessoa que é imortal, de maior ou menor "luz" (evolução espiritual), que encarna sucessivamente em diversos personagens ao longo da história humana e que, ao se apresentar nos terreiros, pode assumir diversas "roupagens" ou "faixas vibratórias", conforme o exemplificam as narrativas registradas a respeito de uma das mais famosas entidades espirituais do Centro, conhecida como Caboclo Tabajara. Este, embora apareça sob a "faixa vibratória" de caboclo no terreiro, aparece sob a forma de exu na casa grande (nome pelo qual não apenas neste Centro mas em boa parte dos terreiros desta região do interior de São Paulo é conhecido - local de culto às entidades responsáveis por zelar pelos aspectos mundanos da existência humana, a chamada "esquerda" umbandista, particularmente exus e pombagiras), sob a designação de "Seu Sete". Tais "roupagens" estão longe de serem arbitrárias. Ao contrário, a forma que um espírito toma, em determinado momento, tem uma função específica para cada ritual. Dessa maneira, no exemplo citado, a mesma entidade, concebida como um espírito de luz, pode tomar a forma de Tabajara se precisa trabalhar no terreiro propriamente dito e atuar junto aos caboclos, realizar cruzamentos, cirurgias e 
consultas de saúde; mas pode também tomar a forma de Seu Sete, se precisa trabalhar junto aos exus na Casa Grande, realizar rituais de desobsessão e outras práticas similares.

Esta forma de apresentação de uma mesma entidade está, portanto, intimamente ligada à interpretação que o consulente recebe sobre sua problemática: se trata-se de um caso leve, em que a responsabilidade sobre a situação do consulente se deve mais a seus atos e hábitos do que à influência de espíritos "mal intencionados", ele será tratado por um caboclo. Se trata-se de um caso em que o agravamento do caso envolve inclusive influência de espíritos "menos evoluídos", ele será tratado por um exu. Neste caso, exu e caboclo podem ser uma mesma entidade que, em si, não tem nenhuma roupagem, sendo melhor definida como uma "luz" inominável.

Tendo isso em vista, o destaque concedido ao indígena na LBMJ não parece proceder da imposição de uma hierarquia que subordine pretos-velhos e exus a uma posição de subalternidade. Em primeiro lugar, porque trata-se (segundo a descrição do Centro) das mesmas entidades que se apresentam sob uma ou outra forma, dependendo da função a ser desempenhada. No fundo, independentemente de aparecer como exu, preto-velho ou caboclo, trata-se sempre da mesma luz espiritual, sem forma fixa. Em segundo lugar, tal fato pode ser interpretado como uma corroboração da hipótese de Santos (1995) a respeito da necessidade lógica do culto aos caboclos em rituais de matriz africana, por se tratarem dos "donos da terra".

Além disso, não deixa de se tratar de uma contestação da efetiva ordem colonial: o índio, antigo senhor da terra, materialmente derrotado, continua a ser espiritualmente considerado o verdadeiro senhor, não o colonizador. Mais do que uma inversão da ordem social, conforme, a propósito da umbanda refere Maggie (2001) e Birman (1985), desautoriza-se, simbolicamente, a expropriação colonial.

Ainda a respeito da suposta desafricanização da umbanda branca vinculada ao enfraquecimento do culto aos exus, sugerida por Diana Brown (1994), haja vista que na LBMJ, não obstante o velamento do culto aos exus, afirma-se praticamente o oposto. A Casa Grande (seu lugar de culto) foi referida pela Cabocla Jupira como "a casa de força maior". Essa qualificação guarda, ao mesmo tempo, significados tanto relacionados à grande importância e poder desse ritual, como também uma certa cautela em relação a um local cujo nome se evita proferir, não por se ter "esquecido", ou "erradicado", mas por ser muito presente e forte.

\section{A doença e a morte}


Todas as práticas de saúde na umbanda, que envolvem uma série de elementos rituais, prescrições e formas de cuidado em relação à doença envolvem também uma forma bastante particular de concebê-la. Montero (1985) conceitua como desordem a experiência da doença na umbanda, pois a doença seria para a autora tanto a causa quanto a expressão do que ela denomina uma situação de "anomia", em que o indivíduo doente personifica uma desordem mais ampla, social e espiritual.

Sem dúvida a condição da doença pode remeter a esse tipo de desordem e de diluição do próprio ser, na linha do que esta autora retoma de Bastide (1983). Mas pelo menos na LBMJ não se trata apenas disso. No Centro estudado, a doença parece surgir como um sinal de pertencimento àquela "família". Todos os consulentes que ali aparecem são interpretados como fazendo parte dessa família e a doença, nessas pessoas, aparece como um chamado a reintegrar-se a ela.

Se eventualmente passam a fazer parte do corpo de médiuns do Centro e se ausentam por um longo período, muitos médiuns relatam o aparecimento de algumas doenças, o que é interpretado como um chamado para retornar ao Centro:

\footnotetext{
“To com essa gripe faz um mês. Aí chegava a hora de ir pro centro, eu ficava com aquela moleza, e não ia. Aí hoje eu falei "ah, é hora de voltar, senão não vai sarar" (depoimento de uma médium do centro).
}

Mesmo aquele que lá procura ajuda e não consegue se curar, vindo a falecer, nem por isso seria menos membro da "família". É reintegrado á mesma em "outro plano", junto às antigas entidades. Talvez por isso não sejam de surpreender as mortes por doenças graves e longas, em cuja cura a LBMJ é especialista, de alguns dos médiuns principais do culto, como por exemplo a do médium fundador, Roberto Zerbetto, e mais recentemente de importantes lideres e médiuns de destaque como Luiz Paiz e Ivone Fernandes. Esta questão, aparentemente contraditória, pode ser perfeitamente abarcada pela lógica da Legião Branca a esse respeito, visto que toda doença é entendida como tendo etiologia espiritual e muitas vezes revela questões de outras vidas a serem "resgatadas" na experiência da vida atual.

Trabalhar curando doenças pode fazer parte de uma missão, cuja prova final é a experiência concreta e pessoal do adoecimento. Terminado o resgate, ou seja, cumprida a prova, a doença e a morte pode surgir como uma redenção, um sinal de que a missão foi cumprida, permitindo ao espírito do médium que integre um plano mais elevado junto ao núcleo da família fundadora. 
É importante não esquecer o papel da morte numa narrativa de fundação da LBMJ. A história desta aldeia espiritual começa com a "morte" da tribo indígena. Morrer adquire, portanto, um sentido de início ou recomeço, e não de fim, concepção compatível com a noção espírita segundo a qual a verdadeira vida é posterior à morte e de certo modo é a sua perspectiva que permite dar sentido e estruturar o sentido da vida terrena.

O curador, na LBMJ, é muitas vezes um antigo consulente que, procurando solução para algum problema de saúde, tornou-se médium. Note-se a ausência de cisão radical entre doente e curador. O afectado pela doença recebe a empatia do mais evoluído, é socorrido e cura-se (especialmente do "esquecimento" da sua origem). Mas o mais evoluído poderá ter tido, e reconhecer-se, na afecção do outro. Ao incumbir-se do próximo, retoma a cura de si e um sentido de vida debruçado ao "patológico", um saber lidar com o sofrer em si e por extensão em todos. Daí um senso de união, familia, ou comunidade. O saber "médico" é usado para aproximar curador (a entidade) e doente (o consulente).

Além da fé, a união e a caridade emergem como valores fundamentais, autenticando uma filiação da instituição a um etos cristão, não obstante a indisponibilidade dos seus 'guias' para se vergarem a uma tradição teológica e se subordinarem a alguma instituição eclesiástica.

\section{Conclusão}

A umbanda branca apresenta-se fundamentalmente como um culto a caboclos que, de certa forma, espelha ou revela a caboclidade (mestiçagem) dos consulentes. Ao dizer que em última análise todos são índios e potencialmente moradores da colônia espiritual "Estrela da Guia" estabelece-se em diálogo com o espiritismo "branco" kardecista do Nosso Lar (XAVIER, 1944), sublinhando que, à diferença desse, nem sempre nem apenas somos "europeus", médicos brancos, ex-padres ou ex-freiras: no caso da Estrela da Guia, os médicos são índios. O suposto "nacionalismo" deste culto não é o das elites fundadoras do país, então e ainda hoje material e espiritualmente moradoras de "casas grandes". Propõe-se mais como um nativismo, socialmente terapêutico de identidades étnicas "apagadas" e espiritualmente inversor de derrotas no plano da história material. A vítima de etnocídio, o índio "morto", retorna espiritualmente para curar e salvar a sua descendência.

O extermínio físico como estratégia de dominação e de aniquilamento nunca terá sido completamente eficiente, posto que segundo a concepção da Legião Branca Mestre Jesus a doença não é em si mesma um mal e o morrer ainda menos. O objetivo do culto é uma 
purificação e um retorno à origem. Dessa maneira, ficar doente não é apenas um chamado mas também, de certa forma, um sinal de que se trata de alguém especial. Assim como, para o cristianismo, muitos são os chamados mas poucos os escolhidos, a oportunidade do chamado da doença permite escolher um caminho espiritual de retorno à aldeia eterna, a uma pátria espiritual.

Tal interpretação poderia incluir e justificar esses episódios de, ao final da missão, alguns médiuns muito especiais, se excelerem tomando em si um tipo de patologia que "queime" os últimos resíduos de impurezas que pudessem estar associados aos seus seres, "poupando-os" assim de manterem laços com este plano. De fato, numa perspectiva espiritualista, a doença parece revelar um significado ligado a um chamado, um caminho de cura pelo ordenamento da verdadeira natureza espiritual do ser humano, em vez de ter uma acepção de mal pura e simplesmente.

O mesmo raciocínio pode associar-se à questão da morte. Ao adentrar num culto espírita, qualquer um, concomitantemente, mesmo que inconsciente ou inadvertidamente, está permanentemente adentrando e entrando em contato com uma rica e profunda simbolização da morte, visto que os parceiros do culto são mortos. No caso da LBMJ, conforme o mito de fundação já analisado (extermínio de uma tribo indígena em torno de mil e quinhentos) foram mortos por uma ordem social injusta. Ainda assim, cuidam dos vivos, mas em si mesmos estão salvos pelo cristianismo, pois o Salvador unanimemente admitido é um morto que ressuscitou espiritualmente. O sentido das orientações vai em direção ao desapego da matéria e do mundano, um apelo a uma dedicação a um sentido da vida que vá alem do corpo físico. Portanto, o culto permite simbolizar a morte e de alguma forma reorganizar a vida em função da própria finitude, algo de que, de certa forma, a sociedade contemporânea parece ter se "esquecido", com a sua apologia a uma saúde idealizada, que acaba por negar a mortal condição humana.

Nota-se também que, através das concepções de doença e morte da LBMJ, há uma intensa ligação destes temas às idéias de família e pertencimento, sempre presentes na valorização dos ideais de caridade, no acolhimento àqueles que chegam até lá, o que rompe com a idéia de morbidade. Ligada ao significado da doença, estão questões como a própria identidade. A cura, portanto, segundo as concepções da LBMJ, não envolve apenas a remissão dos sintomas, mas também uma profunda ressignificação da própria vida e da possibilidade de curar.

Em princípio, não se pode ignorar que esta ressignificação parece marcada por um forte compromisso para com um ideário cristão. No entanto, em larga medida, não parece seguro que a forma que este assume pudesse facilmente satisfazer os critérios de missionários e teólogos católicos. Esta aparente submissão combina-se à 
reafirmação de uma sobrevivência mítica do indígena, elevado, no lugar do missionário, à posição máxima no panteão e capaz de ter a sua participação na história desrecalcada do olvido da morte para reaparecer "curando" os seus "parentes" e descendentes.

Nesta direção, o ritual específico de Santa Rita e a história mítica da LBMJ parecem constituir-se numa replicação metafórica em miniatura do encontro e desencontro entre colonizadores e suas vítimas africanas e indígenas, e como que um vestígio contemporâneo, a céu aberto, de vestígios de conflitos históricos e cicatrizes da alma e cultura brasileira, cuja explicação e tratamento estão longe de ser curados e cuja profundidade e necessidade de manifestação pode calar profundamente em muitos brasileiros, especialmente em momentos de aflição e de recolhimento para as suas raízes, comuns em situações de enfrentamento de ameaças ou desafios à vida.

A todos, o que a LBMJ diz é que são "irmãos" e devem ajudar-se mutuamente. Mas também revela que os seus pais são índios e que, não obstante a sua derrota histórica para os colonizadores, sobreviveram à morte e ao olvido, e desse lugar espiritual ou simbólico podem retornar para os devolver e se devolver à vida ou os garantir contra a morte.

Ironia inconsciente e coletivamente performada, nem a finitude individual nem a dizimação coletiva padecem de sentido e o recalcado retorna vitorioso da "morte", como imortal, para regenerar a letra morta da "missão evangélica" da colonização, nem mais nem menos do que pelas mãos das suas primeiras vítimas.

\section{Referências}

BAIRRÃO, J. F. M. H. Caboclas de Aruanda: a construção narrativa do transe. I maginário, São Paulo, v.9, n.2, p 285-322, $2003 a$.

BAIRRÃO, J. F. M. H. A escuta participante como procedimento de pesquisa do sagrado enunciante. Estudos de Psicologia, Natal,v. 10, n.3, p 441-446, 2005.

BASTIDE, R. Estudos Afro-Brasileiros. São Paulo: Perspectiva, 1983.

BELZEN, J. A. Para uma psicologia cultural da religião: princípios, enfoques, aplicação. Aparecida: I déias \& Letras, 2010.

BIRMAN, P. O que é umbanda. São Paulo: Brasiliense, 1985. 109 p. BROWN, D. D. G. Religion and politics in urban Brazil. Nova I orque: Columbia University Press. 1994.

CAMARGO, C. P. C. Kardecismo e umbanda. São Paulo: PioneiraEdusp. 1961.

CAVALCANTI, M. L. V. C. O Mundo invisível. Rio de Janeiro: Zahar Editores. 1983. 
DEVEREUX, G. De La ansiedad al método en las ciencias del comportamiento. Buenos Aires: Siglo XXI Editores. 1997.

LUTZ, C. A. Unnatural emotions: everyday sentiments on a micronesian atoll and their challenge to Western theory. Chicago: University of Chicago Press. 1992.

LEGIÃO BRANCA MESTRE JESUS. Apostila do Curso de médiuns. Santa Rita do Passa Quatro, 98 p. Trabalho não publicado.

MAGGIE, Y. Guerra de orixá: um estudo do ritual e do conflito. Rio de Janeiro: Jorge Zahar Editor, 2001. 181 p.

MAGNANI, J. G. C. Doença mental e cura na umbanda, Teoria e Pesquisa, Brasília, v. 40, n. 41, Jan/Jul. 2002. Disponível em: <http://www.n-a-u.org/magnanidioencaecuran- aumbanda.html>. Acesso em 10 jun. 2011.

MONTERO, P. Da doença à desordem: a magia na umbanda. São Paulo: Graal. 1987.

NEGRÃO, L. N. Magia e Religião na Umbanda, Revista USP, São Paulo, n. 31, mar/mai, 1989.

RIBAS, O. Ilundo: espíritos e ritos angolanos. Luanda: Instituto de Investigação Científica de Angola. 1975.

SANTOS, J. T. O dono da terra. Salvador: Sarah Letras, 1995.

ROTTA, R. R. Espíritos da Mata: sentido e alcance psicológico do uso ritual de caboclos na Umbanda. 2010.130f. Dissertação (Mestrado em Psicologia) da FFCLRP-USP. 2010.

XAVIER, F.C. Nosso lar (Pelo Espírito André Luiz). Brasília: FEB.1944

\section{Endereço para correspondência}

Daniela Torres de Andrade Lemos

Faculdade de Filosofia, Ciências e Letras de Ribeirão Preto

Departamento de Psicologia - Laboratório de Etnopsicologia

Av. Bandeirantes, 3900 - CEP 14040-901 - Bairro Monte Alegre, Ribeirão Preto - SP -Brasil

Endereço eletrônico: danielatalemos@yahoo.com.br

José Francisco Miguel Henriques Bairrão

Faculdade de Filosofia, Ciências e Letras de Ribeirão Preto

Departamento de Psicologia - Laboratório de Etnopsicologia

Av. Bandeirantes, 3900 - CEP 14040-901 - Bairro Monte Alegre, Ribeirão Preto - SP

- Brasil

Endereço eletrônico: bairrao@usp.br

Recebido em: 02/08/2011

Reformulado em: 09/10/2012

Aceito para publicação em: 19/12/2012

Acompanhamento do processo editorial: Adriana Benevides Soares

\section{Notas}

* Bacharel em Psicologia e Psicóloga pela FFCLRP-USP. Mestranda do programa de pós-graduação em psicologia da FFCLRP-USP.

**Professor Livre-Docente. Graduado em Psicologia pelo IP-USP e em Filosofia pela FFLCH-USP. Doutor em Filosofia pela UNICAMP e Livre-Docente pela FFCLRP-USP. Coordenador do Laboratório de Etnopsicologia do Departamento de Psicologia da 
Daniela Torres de Andrade Lemos, José Francisco Miguel Henriques Bairrão Doença e Morte na Umbanda Branca: A Legião Branca Mestre Jesus

Faculdade de Filosofia, Ciências e Letras de Ribeirão Preto, Universidade de São Paulo. 